\title{
Could Ramadan catalyze SARS-CoV-2 spread? Preliminary results
}

\author{
Andrzej Jarynowski ${ }^{1}$, Daniel Płatek ${ }^{2}$ \\ 1 Interdisciplinary Research Institute in Wrocław, Poland. \\ ajarynowski@interdisciplinary-research.eu
}

2 Polish Academy of Sciences, Institute of Political Studies, Warsaw, Poland.

\begin{abstract}
Around 1.8 billion Muslims worldwide celebrate in some extent the holy month of Ramadan during COVID-19 pandemic. Some increase their attendance worship sites and traditional dining in extended families, so infectious contact rates could increase. Moreover, fasting could increase the probability of acquiring SARS-CoV-2 infection. There are mitigation measures (e.g. Healthy Ramadan by WHO) applied to reduce the SARS-CoV-2 spread, however their real impact is still unknown. Multiple studies assessed observed effects of contact rates increase during holidays as Chinese New Year in January and Passover and Easter in April and their short-time effects on COVID-19 transmission dynamics. However, there are any quantitative attempts considering epidemiological consequences of the holy Ramadan (at least up to our knowledge and keywords search in various databases until the submission day). We analyze the fractions of Muslims and time series of COVID-19 daily incidence and cases numbers for 197 countries and territories. We found statistically significant positive link with proportion of Islam adherents with increase in normalized new cases of COVID-19 during 1-18 May 2020. Moreover, growth of incidences in May is statistically significantly greater than in a control (April).
\end{abstract}

\section{Problem Introduction}

The COVID-19 case registry (ECDC 2020) and proportion of Muslim population fractions (Pew 2020) give an opportunity to compare possible role of the holy Ramadan in disease propagation. Religious norms are rules that prescribe what people should and should not do in a social environment. Celebration of Easter and Passover in 2020 affected contact patterns to a large extent worldwide (especially in Europe), but only in the short-term of a few days only (Chen, et al. 2020). However, the holy Ramadan lasts much longer, so a possible effect on SARS-CoV-2 transmission dynamics could be greater. Moreover, concerning the meaning ascribed to eating, Ramadan stands in contrast to everyday musilm practices. When eating is usually considered as a private act, during Ramadan it becomes a collective act.

While the traditions associated with fasting and gathering in worship sites with Ramadan this month (23.04-23.05.2020 CEST) are well established, they could affect SARS-CoV-2 spread. People are instructed by authorities (WHO 2020) by advising on physical distancing; encouraging healthy hygiene; frequently cleaning worship sites, etc.

But how will adherence to healthy instructions or religious norms affect the pandemic shape? Disregarding medical and all other differences, we are trying to investigate the 
relative religious adherence to predict relative penetration of COVID-19 pandemic internationally during 1-18 May 2020.

\section{State of the art and Working hypothesis}

There are plenty of attempts (Khan \& Lehebi, 2020; Yaqub, et al., 2020) to link fasting (issues as dehydration, lower physical activity levels, sleeping rescheduling, an inability to take medications) with immunity deficiency and higher risk of being infected with SARS-CoV-2 or developing severe illnesses. Traditionally sharing meals, iftar and suhur, with a greater number of people and praying together in worship sites could increase infectious contacts.

However, up to our knowledge, there is no study showing quantitative links between Ramadan and the spread of SARS-CoV-2. Our working hypothesis is that Muslims undergo various lifestyle changes during Ramadan, which could lead to:

- increase of infectious contact rates (sharing meals and praying together in worship sites);

- increase of infection probability per contact (immunodeficiency due to fasting).

We decided to start our observation since 1st of May due to disease incubation period and the last day is 18.05.2020.

This is important to mention, that compliance with authorities measures (e.g. healthy Ramadan by WHO (WHO 2020)) could at the same time decrease infectious contact rate (by physical distancing) or decrease probability of infection per contact (by healthy hygiene and cleaning worship sites).

\section{Measurable variables and data curing}

We have correlated infection dynamics with Muslim population in for each country with available indexes as:

- \% of Muslim - proportion of Islam adherents in the country (Pew 2014).

- regression in cases - linear regression coefficient between daily case series and consequential days in a given period (May or April) for each country. It tells us what are the trends in the total number of cases.

- regression in incidence - linear regression coefficient between daily incidence per 100000 inhabitants series and consequential days in a given period (May or April) for each country. It tells what are the trends in incidence.

- regression in normalized cases - linear regression coefficient between daily case series and consecutive days in a given period (May or April) divided by mean of daily number of cases in a given period for each country. It tells what are the trends in the number of cases, with 1 to be the mean number of normalized cases.

Positive regression value means an increasing trend in a given observable (incidence and normalized cases); negative otherwise; 0 means stable situation. 
We include for analysis these countries, which reported new infection cases for each day in the respective time period May - with possible effect of Ramadan (96/89 countries) and April - control (147 countries).

\section{Results}

We can see a relationship in linear regressions [Tab. 1] between regression in incidence/ normalized cases and \% Muslims in May (possibly affected by Ramadan) and April (Control).

\begin{tabular}{|c|c|c|c|c|c|c|}
\hline \multirow[b]{2}{*}{ Predictors } & \multicolumn{2}{|c|}{$\begin{array}{c}\text { Regression in normalized } \\
\text { cases in May } \\
\end{array}$} & \multicolumn{2}{|c|}{$\begin{array}{c}\text { Regression in } \\
\text { incidence in May }\end{array}$} & \multicolumn{2}{|c|}{$\begin{array}{c}\text { Control: Regression in } \\
\text { normalized cases in April }\end{array}$} \\
\hline & Estimates & $\mathrm{p}$ & Estimates & $\mathrm{p}$ & Estimates & $\mathrm{p}$ \\
\hline (Intercept) & -0.01 & 0.544 & -1.23 & 0.712 & -0.15 & 0.967 \\
\hline$\%$ of Muslims & 0.0004 & 0.036 & 0.09 & 0.104 & 0.01 & 0.9 \\
\hline $\begin{array}{l}\text { Observations } \\
\text { (Countries) }\end{array}$ & & 89 & & 96 & & 147 \\
\hline $\mathrm{R}^{2} / \mathrm{R}^{2}$ adjusted & $0.049 / 0.038$ & & $0.028 / 0.017$ & & $0.000 /-0.007$ & \\
\hline
\end{tabular}

Tab. 1) Linear regressions with dependent variables describing infection dynamics with possible effect of Ramadan (in May) or retrospective control (in April) and independent variable - a proportion of Muslims for each country.

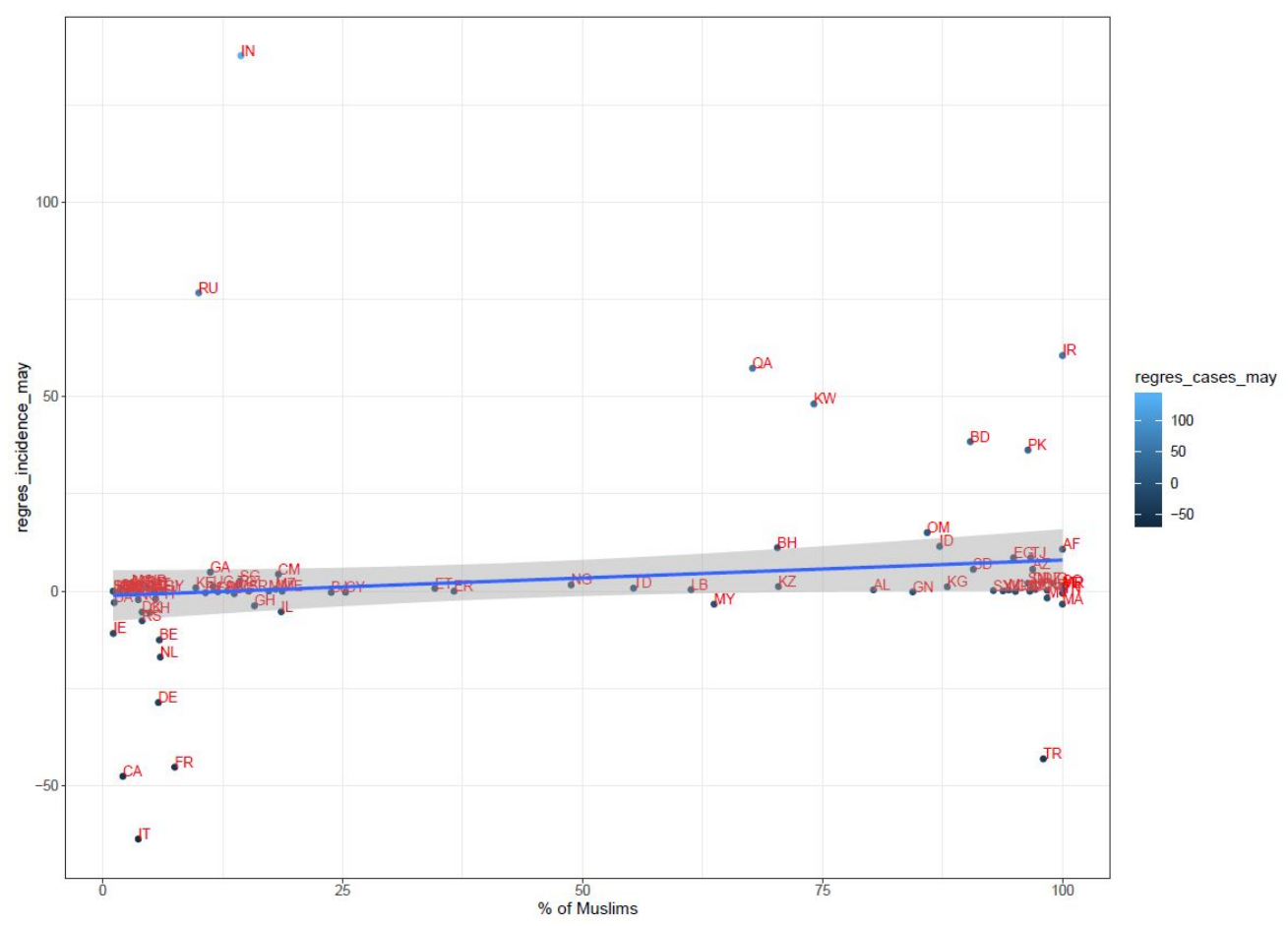


Fig. 1) Scatter plot between regression in incidences and \% of Muslims (plotted only countries $>1 \%$ ) with linear trend line in Mai 2020. Node's color corresponds to regression in a number of cases.

There is an insignificant relationship positive association between incidence and \% of Muslims [Fig. 1, Tab. 1].

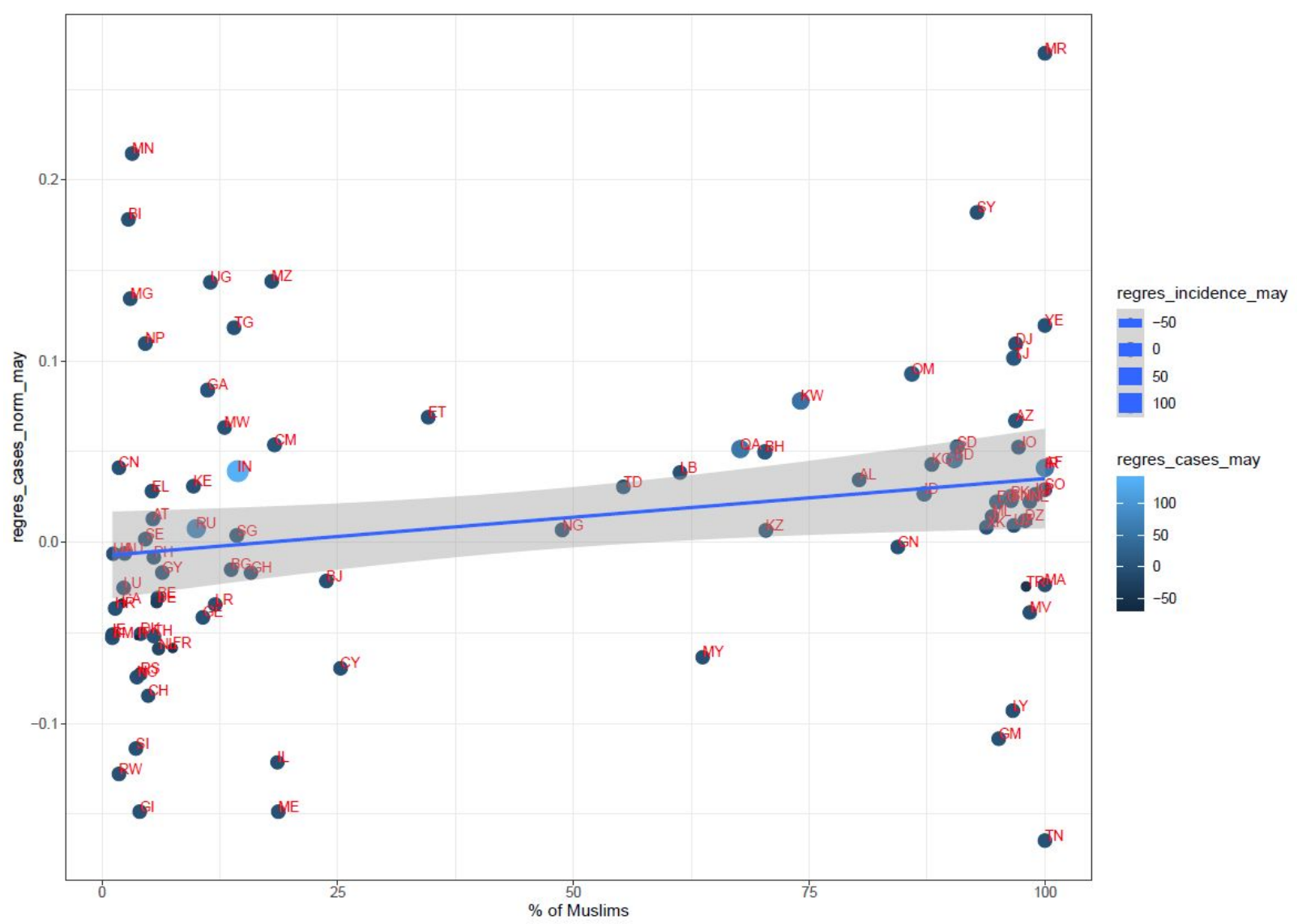

Fig. 2) Scatter plot between regression in normalized cases and \% of Muslims (plotted only countries $>1 \%$ ) with linear trend line in Mai 2020. Node's color corresponds to regression in a number of cases. Node's size corresponds to regression in incidence.

There is a statistically significant relationship ( $p$-Value $<.05$ ) between regression of cases and $\%$ of Muslims [Fig. 2, Tab. 1].

As a control, let compare regressions in April, where we do not see any relationship between infection dynamics and proportion of Muslims [Fig. 3, Tab. 1].

Increasing trends in COVID-19 cases in countries with higher Islam adherents fraction in May (and no such a link in control month April) could by potentially explained by the increased infectious contact rates or/and inceased infection probability due to changing eating habits during of the holy Ramadan. 


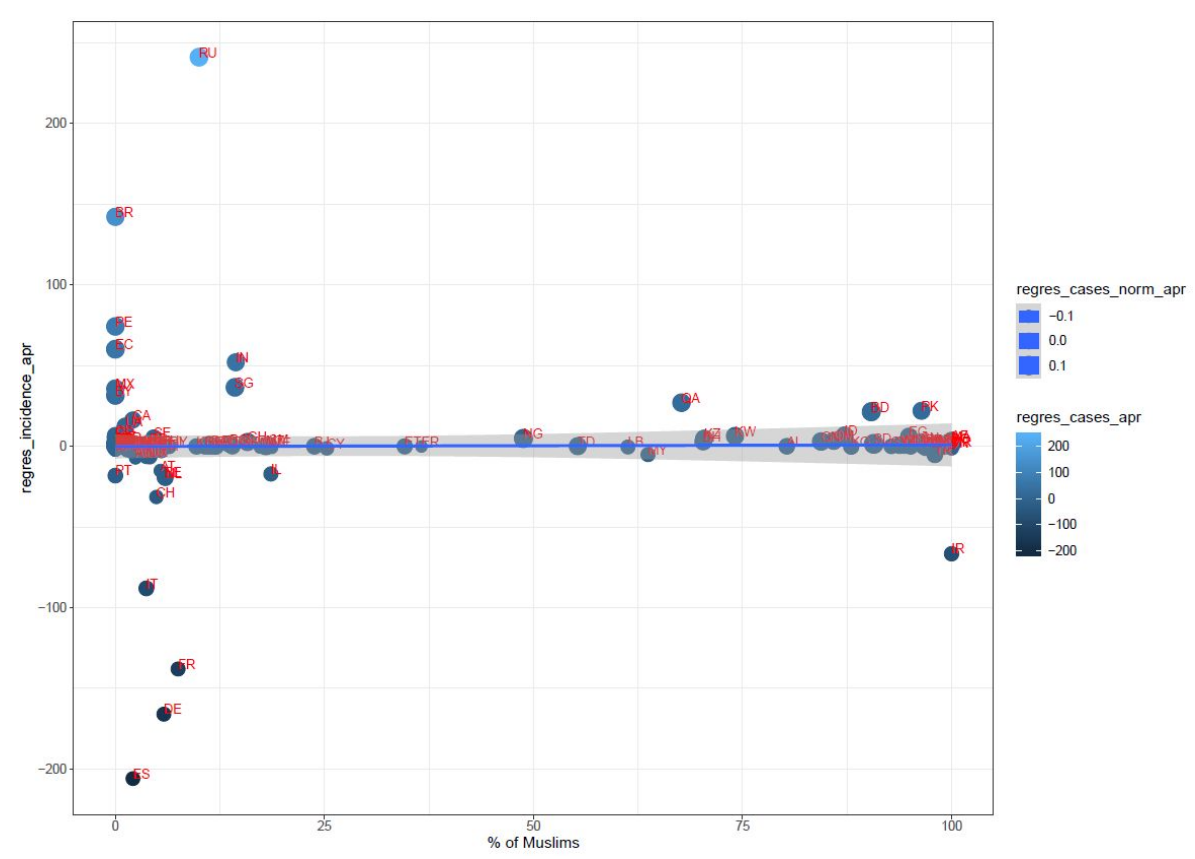

Fig. 3) Scatter plot between regression in incidences and \% of Muslims (plotted only countries $>1 \%$ ) with linear trend line in April 2020. Node's color corresponds to regression in a number of cases. Node's size corresponds to regression in a normalized number of cases.

Moreover, one side t-test (for countries with \% of Muslims $>10$ ) between regression in incidences in May ([Fig. 1] Ramadan, mean=7.3) vs regression in incidences in April ([Fig. 3] control, mean $=2.05$ ) shows statistically significant increase in incidence ( $\mathrm{df}=56$, $\mathrm{p}$-value $=0.04$ mean of the differences $=5.25$ ).

\section{Conclusions}

We showed that there is a statistically significant positive relationship between the proportion of Muslims and increase of COVID-19 cases in May 2020 and we proved that incidences during Ramadan period (May) are statistically significantly greater than during control (April).

Ramadan is more or less celebrated this pandemic year by 1.8 billion Islam adherents, making up about 24\% world population. The results emphasize the need to pay more attention to sociological (Jarynowski, et al. 2020) and cultural context when comparing outbreak dynamics and mitigation strategies between countries.

However, there are plenty of limitations of this illustrative study. Increased cases could be an artefact of better surveillance in this special time in Muslim populations. During Ramadan this year, some counties closed mosques (e. g. Norway) some not (e. g. Germany). There are also various adherence levels to Ramadan rules within Muslims worldwide 
e.g. $20 \%$ in Morocco and $90 \%$ in UAE (Statista 2020). Moreover, compliance to hygienic and physical distancing measures differ significantly between countries (EU 2020).

Concluding for a short-term impact of Ramadan during a pandemic (beyond the first 18 days of May) is still unknown and a complete picture will be available probably 2-4 week after Ramadan finishes with additional control in COVID-19 deaths and in policy variations, medical system, climate, arrival times, seroprevalence, etc in different countries too.

Acknowledge: Codes and data available on https://github.com/ajarynowski/koronawirus and in simplified version on https://www.kaggle.com/andrzejjarynowski/ramadan-catalyze-sars-cov-2-spread.

\section{Literature}

Chen, S., Igan, D., Pierri, N., \& Presbitero, A. F. (2020). Tracking the Economic Impact of COVID-19 and Mitigation Policies in Europe and the United States.

ECDC (2020) COVID-2019 Data https://opendata.ecdc.europa.eu/covid19/casedistribution/csv

EU (2020) The Health System Response Monitor (HSRM) https://www.covid19healthsystem.org/mainpage.aspx

Jarynowski, A., Wójta-Kempa, M., Płatek, D., \& Belik, V. (2020). Social Values Are Significant Factors in Control of COVID-19 Pandemic-Preliminary Results.

https://www.preprints.org/manuscript/202005.0036/download/final file

Khan, M. H., \& Al-Lehebi, R. (2020). Respiratory disease and Ramadan. The Lancet Respiratory Medicine, 8(5), 449-450.

Pew Research Center (2015) Religious Composition by Country https://www.pewforum.org/2015/04/02/religious-projection-table/2010/percent/all

Statista 2020 https://www.statista.com/topics/3796/ramadan-2017/

WHO (2020) Safe Ramadan practices in the context of the COVID-19 https://apps.who.int/iris/bitstream/handle/10665/331767/WHO-2019-nCoV-Ramadan2020.1-eng.pdf

Yaqub, S., Rana, M. U., \& Aukrust, P. (2020). Ramadan during the COVID-19 pandemic. Tidsskrift for Den norske legeforening. 